\title{
Correlation between serum leptin and bone mineral density in hemodialysis patients
}

\author{
Mahin Ghorban-Sabbagh ${ }^{1}$, Fatemeh Nazemian ${ }^{2 *}$, Massih Naghibi ${ }^{2}$, Mohammad-Taghi Shakeri ${ }^{3}$, Saeedeh \\ Ahmadi-Simab $^{4}$, Reza Javidi-Dasht-Bayaz ${ }^{5}$ \\ ${ }^{1}$ Kidney Transplantation Complications Research Center, Montaseriyeh Organ Transplantation Hospital, Mashhad University of Medical Sciences, \\ Mashhad, Iran \\ ${ }^{2}$ Nephrology Section, Department of Internal Medicine, Imam-Reza Hospital, Mashhad University of Medical Sciences, Mashhad, Iran \\ ${ }^{3}$ Department of Community Medicine and Public Health, Ghaem Hospital, Mashhad University of Medical Sciences, Mashhad, Iran \\ ${ }^{4}$ Cancer Research Center, Mashhad University of Medical Sciences, Mashhad, Iran \\ ${ }^{5}$ Faculty of Medicine, Mashhad University of Medical Sciences, Mashhad, Iran
}

\section{A R T I C L E I N F O}

Article Type:

Original

\section{Article History:}

Received: 17 May 2016

Accepted: 1 July 2016

Published online: 22 July 2016

\section{Keywords:}

Hemodialysis

Leptin

Bone mineral density

Dual-energy x-ray absorptiometry

\begin{abstract}
A B S T RAC T
Introduction: For diagnosing of specific types of bone lesions in hemodialysis (HD) patients, it is necessary to conduct a bone biopsy as the gold standard method. However, it is an invasive procedure. While different markers have been suggested as alternative methods, none of them has been selected. The frequency of hip fractures is 80 fold in HD patients who have two-fold mortality as compared with general population.

Objectives: Recently, serum leptin has been suggested as a bone density marker. This study tries to confirm this proposal.

Patients and Methods: In this study about $104 \mathrm{HD}$ patients (53.8\% male and $46.2 \%$ female) were enrolled. The average age was $38.28 \pm 7.89$ years. Serum leptin, bone alkaline phosphatase, intact parathyroid hormone (iPTH), 25(OH)D, calcium, phosphorus and bone mineral density (BMD) (at the femoral neck and lumbar spine, as measured by dual-energy $\mathrm{x}$-ray absorptiometry [DXA]) were assessed.

Results: Analysis by polynomial regression revealed no correlation between BMD Z-score at two points and serum leptin level. According to the thresholds of $25 \mathrm{ng} / \mathrm{mL}$ and $18-24 \mathrm{ng} / \mathrm{mL}$ in some studies, we detected $25 \mathrm{ng} / \mathrm{mL}$ as the threshold in our patients. Under this threshold, the leptin effect on bone mass was negative, and above the threshold of $25 \mathrm{ng} / \mathrm{mL}$, we found leptin had positive effect on bone mass.

Conclusion: In this investigation, we found, leptin has a bimodal effect on bone mass. Cortical bones assessment may be a better option for assessment.
\end{abstract}

Implication for health policy/practice/research/medical education:

In a study on $104 \mathrm{HD}$ patients, we found, serum leptin has a bimodal effect on bone mass.

Please cite this paper as: Ghorban-Sabbagh M, Nazemian F, Naghibi M, Shakeri MT, Ahmadi-Simab S, Javidi-Dasht-Bayaz R.

Correlation between serum leptin and bone mineral density in hemodialysis patients. 2016;5(3):112-117. DOI: 10.15171/jrip.2016.24

\section{Introduction}

Chronic kidney disease-mineral and bone disorder (CKD$\mathrm{MBD}$ ) is a familiar term for clinicians and nephrologists since 2005. All hemodialysis (HD) patients have different percentages of bone involvement. Except "bone biopsy" until now, scientists have not found an exact non-invasive way for detecting the type and degree of bone involvement in this group of patients. Bone densitometry does not reliably predict fracture risk in patients with glomerular filtration rate $(\mathrm{GFR})<45 \mathrm{~mL} / \mathrm{min} / 1.73 \mathrm{~m}^{2}$ and neither does it predict the type of renal osteodystrophy (KDIGO 2012) however, recent data support that dual-energy $\mathrm{x}$-ray absorptiometry (DXA) can predict fracture risk in patients with CKD. Importantly, DXA remains an inexpensive and widely available technique that can easily be standardized across sites. Given this reliability, DXA is likely to be a good tool in longitudinal CKD research studies for the serial assessment of bone mineral density (BMD) in response to interventions (1). But, if we have more knowledge about what happens in the HD bones, leptin is produced predominantly in the adipose tissue. However, it is also expressed in a variety of other tissues, including pla- 
centa, ovaries, mammary epithelium, bone marrow, and lymphoid tissues. Leptin binds to leptin receptors (ObRs) located throughout the central nervous system and peripheral tissues, with at least six identified receptor isoforms (ObRa, ObRb, ObRc, ObRd, ObRe, and ObRf). The kidneys play a significant role in the plasma removal of leptin. Given its size (16000 Da), leptin is freely filtered by the glomerulus. However, while leptin is freely filtered, little or no leptin cleared by the kidneys appears in the urine. Renal processing of leptin appears to occur through renal tubular uptake and cellular degradation $(1,2)$. Although not all patients with CKD have elevated serum leptin levels as reported in some studies, a significant elevation is noted when such levels are adequately corrected for body fat mass and age (2). The leptin that accumulates in patients with CKD is a bioactive and free form and not a protein-bound one, which is most prevalent in lean healthy controls.

In a study, in patients with moderate renal insufficiency (serum creatinine concentration of $2.5 \mathrm{mg} / \mathrm{dL}$ [221 $\mu \mathrm{mol} / \mathrm{L}]$ ) no renal clearance of leptin was observed. The exact cause of elevated serum leptin in CKD patients is not well understood. Various data suggesting that several factors may be involved, including loss of functioning renal mass, dialyzer membranes, dialysis modality, low erythropoietin levels, chronic inflammation and hyperinsulinemia. The results of some studies consistent with relatively high leptin levels caused weight loss in patients with end stage renal disease (3). However, another study found no correlation between serum leptin and weight change in patients with hyperleptinemia and end-stage renal disease (ESRD) (2). Besides being as energy hemostatic hormone, leptin has been shown to be also involved in gonadal maturation and in somatotropic and adrenocorticotropic functions regulating the immune system and body development. It is only recently that it has been found to be involved in bone metabolism as well. In vitro studies have shown that it promotes differentiation of mesenchymal stem cells to osteoblasts rather than adipocytes and inhibits osteoclastogenesis by increasing osteoprotegerin and decreasing RANK-ligand and synthesis (4). Furthermore, in vivo experiments of systemic leptin administration has proved to stimulate bone growth, to increase bone strength and to prevent ovariectomy induced bone loss (5). In contrast, its intracerebroventricular administration in wild or ob/ob leptin deficient mice resulted in bone loss (6). According to various papers about the relation between serum leptin and BMD published between 2007 and 2014, 18 papers showed no correlation between these two elements after adjusting correlation for the age, gender, or hormonal levels among others (7-25). In the remaining four papers, one paper showed a positive correlation among pre-pubertal girls (48 cases) (13). While another paper, showed that leptin is inversely associated to BMD in Brazilian obese adolescents (109 cases) (23). The other study was done on 52 Brazilian HD patients with the average age 57 and certified correlation between leptin and BMD with bone biopsy (25). Finally, the last one showed that leptin was positively related with the whole body and femoral BMD in postmenopausal nondiabetic elderly women (63 cases) (22). However, according to their limited cases, these results should examine in other studies. Moreover, nutritional and drug agents also can affect bone density. For example, long-term warfarin therapy in patients with valvular heart disease and prosthetic heart valves could significantly decrease bone density in lumbar spine region. Therefore, these factors also must be considered in all studies with bone density assessment (26).

\section{Objectives}

In this study we assessed repeatedly the correlation between leptin and BMD in our young and middle-aged HD patients. The majority of prior studies was done on elderly people who may suffer from senile osteoporosis; however, our patients were between 20-55 years old. Moreover, another priority in this study is the sample size of 104 patients. Additionally, the correlation of other laboratory parameters with leptin was also investigated.

\section{Patients and Methods \\ Study population}

This cross-sectional study was carried out between 2010 and 2012 in all HD centers in Mashhad, Iran. Around 115 patients between the ages 20 to 55 , were included to this study, however 104 patients (56 males and 48 females) were eligible to include to the study. All of them were treated by conventional HD about 4 hours with bicarbonate base dialysate and polysulfone membrane, three-times a week and all had $\mathrm{KT} / \mathrm{V} \geq 1.2$ in recent three months. Our patients had at least 6-month history of initiation of their HD. The exclusion criteria consisted of no history of malignancy, glucocorticoid consumption in recent one year ago, previous fracture (from initiation of HD) and previous parathyroidectomy (that can affect bones) or previous history of kidney transplantation.

Assays

All samples were given by expert HD nurses after about 12 hours fasting. The serum obtained after centrifugation was stored in aliquots at $-20^{\circ} \mathrm{C}$ before it was assayed. Body weight and height of all patients were recorded after HD session and body mass index (BMI) $\left(\mathrm{kg} / \mathrm{m}^{2}\right)$ was calculated. All tests were analyzed by enzyme-linked immunosorbent assay (ELISA) method by using German LDN kit for leptin (normal value;3.7-11.1 mean $7.4 \mathrm{ng} / \mathrm{mL}$ for female and 2-5.6 mean $3.8 \mathrm{ng} / \mathrm{mL}$ for male), and intact parathyroid hormone (iPTH) (normal value: $7.6-37 \mathrm{gg} / \mathrm{mL}$ ) and 25 OHVD and bone ALP (bALP) (normal value; 3.7-11.1 U/L) using German IDS kits of immunodiagnostic system kits.

\section{Dual X-ray absorptiometry}

BMD of our patients was measured at femoral neck (as a mixed bone) and lumbar spine (as a cancellous bone) level using DPX-L densitometer (Lunar, Madison, Wis, USA). All BMD measurements were performed by the same ex- 
perienced operator. BMD results were obtained in absolute values $\left(\mathrm{g} / \mathrm{m}^{2}\right)$ in T-scores and $\mathrm{Z}$-scores. T-score is the number of standard deviations (SDs) from the mean BMD for young sex-matched normal controls (20-40 years old) and $\mathrm{Z}$-score is the number of SDs from the mean BMD for age and sex-matched normal population, which allows the comparison of BMD between patients of different ages and genders. The reference values were obtained from Italian normal range.

\section{Ethical issues}

The research followed the tenets of the Declaration of Helsinki. All participants gave their informed written consent to enter the study. Participation in this study was voluntary and patients were thus free to withdraw from the study at any time without having any effect on their treatment process. This study was approved by the ethic committee of Mashhad University of Medical Sciences.

\section{Statistical analysis}

Total number of patients in our study were $104 \mathrm{HD}$ patients, of whom 48 (46.2\%) were female and 56 (53.8\%) were male. As in our statistical analysis, the data are of the type normally distributed, they have been presented in the form mean \pm SD. Data were analyzed by SPSS software (version 16, SPSS Inc., Chicago, IL, USA). We used descriptive statistics, $t$ test, Kolmogorov-Smirnov $\mathrm{Z}$ and correlation for data analysis. In our study, significance was defined when $P<0.05$.

\section{Results}

\section{Demographic and biochemical data}

All our subjects were $104 \mathrm{HD}$ patients, of whom 48 (46.2\%) were female and $56(53.8 \%)$ were male (Table 1). The demographic and biochemical data are shown in Table 1. Female patients were from 22 to 50 years old. Male patients' ages ranged from 20 to 50 years old. Mean \pm SD of serum leptin, iPTH and bALP were $34.03 \pm 22.62$ (ng/ $\mathrm{mL}), 206.51 \pm 174.89(\rho \mathrm{g} / \mathrm{mL})$ and $74.41 \pm 73.62(\mathrm{U} / \mathrm{L})$, respectively.

BMI in our female patients was significantly higher than males $\left(23.65 \pm 3.72 \mathrm{~kg} / \mathrm{m}^{2}\right.$ versus $22.13 \pm 3.45 \mathrm{~kg} / \mathrm{m}^{2}$, $P=0.034)$. Leptin levels were significantly higher in females than males $(39.75$ versus $8.07 ; P<0.001)$. Around 30 patients had leptin levels of $\geq 25 \mathrm{ng} / \mathrm{mL}$ and 68 patients had leptin levels of $<25 \mathrm{ng} / \mathrm{mL}$.

In all patients, a positive significant correlation between leptin and BMI $(P<0.001, P=0.017$ and $P<0.001$, respectively) was detected.

There are no significant differences between two genders among some variables such as age, phosphor, intact PTH and duration on HD. The calcium level was significantly lower in females than males $(8.5 \pm 1.26$ versus $9.03 \pm 1.24)$. The leptin level was significantly higher in females than males $(42.38 \pm 39.75$ versus $13.08 \pm 8.07 \mathrm{ng} /$ $\mathrm{mL})(P=0.0001)$. Vitamin D level was significantly lower in females than males $(13.90 \pm 9.15$ versus $19.70 \pm 8.14 \mathrm{ng} /$ $\mathrm{mL})(P=0.001)$. Women had significantly higher BMI than men $\left(23.65 \pm 3.72 \mathrm{~kg} / \mathrm{m}^{2}\right.$ versus $\left.22.13 \pm 3.45 \mathrm{~kg} / \mathrm{m}^{2}\right)$ $(P=0.026)$. Correlation between serum leptin level and the other variables in two genders are shown in Table 2. Additionally, an inverse significant correlation of serum leptin and vitamin $\mathrm{D}$ level in all patients was detected $(\mathrm{r}=-0.311, P=0.002)$. Correlation between leptin and bALP was negative in both males $(r=-0.17, P=0.223)$ and females $(\mathrm{r}=-0.075, P=0.626)$, and in all groups $(\mathrm{r}=-0.061$, $P=0.548)$, however, none of them was significant. The relation between duration of HD and leptin levels also was negative but not significant $(\mathrm{r}=-0.192, P=0.059)$. There were positive correlations between serum leptin and lumbar T-score $(r=0.236, P=0.027)$ and femoral T-score in all patients $(\mathrm{r}=0.241, P=0.022)$ and also in females $(\mathrm{r}=0.370$, $P=0.013)$. We did not find any correlation between other BMD parameters and leptin level $(P>0.05)$. Lumbar densities in all patients were significantly better than femoral densities $(-0.85 \pm 1.48$ in lumbar region and $-1.09 \pm 1.17$ $\mathrm{g} / \mathrm{cm}^{2}$ in femoral neck region) $(P<0.05)$.

Figures 1 and 2 show the simple regression analysis between $\mathrm{z}$-scores of lumbar and femoral neck regions with leptin levels above and under $25 \mathrm{ng} / \mathrm{mL}$. We observed a correlation between two groups of relations, negative to positive values ( $\mathrm{r}$ : -0.053 in femoral and -0.024 at lumbar

Table 1. Demographic and biochemical markers of our patients (Mean \pm SD)

\begin{tabular}{|c|c|c|c|c|}
\hline & ALL & Female & Male & $P$ value ${ }^{1}$ \\
\hline Age (y) & $38.28 \pm 7.89$ & $38.52 \pm 7.50$ & $38.07 \pm 8.27$ & $\mathrm{NS}^{1}$ \\
\hline$P(\mathrm{mg} / \mathrm{mL})$ & $5.35 \pm 1.84$ & $5.22 \pm 1.90$ & $5.47 \pm 1.79$ & $\mathrm{NS}^{1}$ \\
\hline Ca $(\mathrm{mg} / \mathrm{mL})$ & $8.78 \pm 1.27$ & $8.50 \pm 1.26$ & $9.03 \pm 1.24$ & 0.034 \\
\hline Leptin (ng/mL) & $22.62 \pm 34.03$ & $39.75 \pm 42.38$ & $8.07 \pm 13.08$ & 0.000 \\
\hline iPTH (pg/mL) & $206.51 \pm 174.89$ & $222.42 \pm 166.33$ & $192.6 \pm 182.41$ & $\mathrm{NS}^{1}$ \\
\hline Vitamin D (ng/mL) & $17.04 \pm 9.05$ & $13.90 \pm 9.15$ & $19.7 \pm 8.14$ & 0.001 \\
\hline Duration (y) & $4.85 \pm 4.36$ & $4.65 \pm 4.23$ & $5.03 \pm 4.51$ & $\mathrm{NS}^{1}$ \\
\hline BMI $\left(\mathrm{kg} / \mathrm{m}^{2}\right)$ & $22.83 \pm 3.64$ & $23.65 \pm 3.72$ & $22.13 \pm 3.45$ & 0.034 \\
\hline bALP (U/L) & $74.41 \pm 73.62$ & $77.2 \pm 75.03$ & $72.04 \pm 73.04$ & $\mathrm{NS}^{1}$ \\
\hline Femoral-Z & $-1.13 \pm 1.18$ & $-1.21 \pm 1.14$ & $-1.04 \pm 1.21$ & $\mathrm{NS}^{1}$ \\
\hline Femoral-T & $-1.66 \pm 1.27$ & $-1.63 \pm 1.27$ & $-1.68 \pm 1.28$ & $\mathrm{NS}^{1}$ \\
\hline Lumbar-Z & $-0.85 \pm 1.48$ & $-0.77 \pm 1.46$ & $-0.93 \pm 1.52$ & $\mathrm{NS}^{1}$ \\
\hline Lumbar-T & $-1.30 \pm 1.63$ & $-0.92 \pm 1.72$ & $-1.68 \pm 1.43$ & 0.022 \\
\hline
\end{tabular}

${ }^{1}$ Non-significant. 
Table 2. Correlation between leptin and variables

\begin{tabular}{|c|c|c|c|c|c|c|}
\hline & \multicolumn{2}{|c|}{ All } & \multicolumn{2}{|c|}{ Female } & \multicolumn{2}{|c|}{ Male } \\
\hline & Correlation & $P$ value & Correlation & $P$ value ${ }^{1}$ & Correlation & $P$ value \\
\hline BMI $\left(\mathrm{kg} / \mathrm{m}^{2}\right)$ & 0.43 & $0.000^{*}$ & 0.353 & $0.017^{*}$ & 0.637 & $0.000^{*}$ \\
\hline $\mathrm{P}(\mathrm{mg} / \mathrm{dL})$ & 0.037 & 0.722 & 0.084 & 0.582 & 0.098 & 0.489 \\
\hline $\mathrm{Ca}(\mathrm{mg} / \mathrm{dL})$ & -0.122 & 0.234 & -0.024 & 0.874 & -0.035 & 0.806 \\
\hline Femoral-Z & 0.089 & 0.403 & 0.252 & 0.099 & -0.063 & 0.677 \\
\hline Femoral-T & 0.241 & $0.022^{*}$ & 0.370 & $.013^{*}$ & 0.112 & 0.460 \\
\hline Lumbar -Z & 0.119 & 0.269 & 0.255 & 0.095 & -0.258 & 0.091 \\
\hline Lumbar-T & 0.236 & $0.027^{*}$ & 0.203 & 0.185 & 0.003 & 0.982 \\
\hline Duration on HD (y) & -0.192 & 0.059 & -0.283 & 0.060 & -0.054 & 0.706 \\
\hline $\mathrm{bALP}(\mathrm{U} / \mathrm{L})$ & -0.061 & 0.548 & -0.075 & 0.626 & -0.17 & 0.223 \\
\hline Age (y) & -0.082 & 0.421 & -0.199 & 0.191 & 0.001 & 0.992 \\
\hline iPTH (pg/mL) & -0.026 & 0.799 & -0.083 & 0.587 & -0.138 & 0.325 \\
\hline Vitamin D (ng/mL) & -0.311 & $0.002^{*}$ & -0.217 & 0.157 & -0.200 & 0.154 \\
\hline
\end{tabular}

$* P$ value $<0.05$

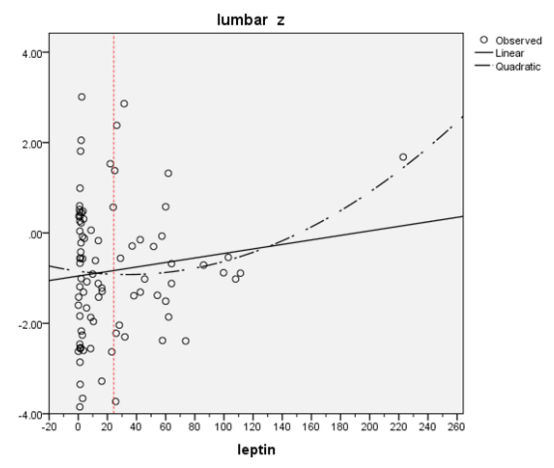

Figure 1. Correlation between lumbar bone density and peripheral serum leptin $(\mathrm{ng} / \mathrm{mL})$ in hemodialysis patients. Polynominal regression analysis with all leptin values: $\mathrm{y}=6.59 \times 10-5 \mathrm{x} 2-4 \times 10-3 \mathrm{x}-0.846, \mathrm{n}=98, \mathrm{r}=0.029, P=0.282$; simple regression analysis for leptin $>24.41 \mathrm{ng} / \mathrm{mL}: \mathrm{y}=0.007 \mathrm{x}-$ 1.099, $n=30, r=0.033, \quad P=0.335$.

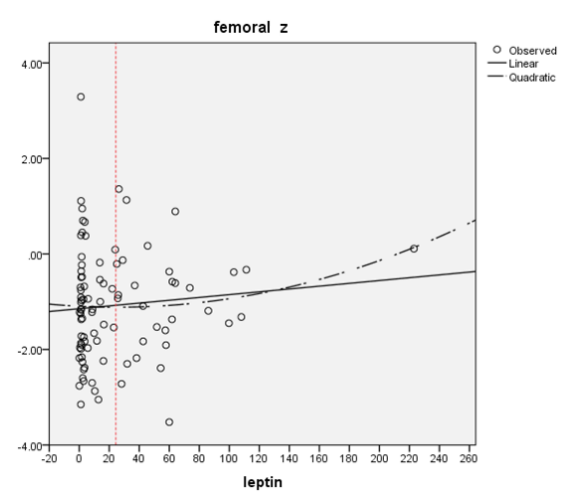

Figure 2. Correlation between femoral neck bone density and peripheral serum leptin $(\mathrm{ng} / \mathrm{mL})$ in hemodialysis patients. Polynomial regression analysis with all leptin values: $y=3.2 \times 10-5 x 2-2 \times 10-3 x-1.096, \quad n=98, \quad r=0.014, \quad P=0.55$; simple regression analysis for leptin>24.41 ng/mL: $y=0.003 x-$ 1.133, $n=30, r=0.011, P=0.575$.

region in leptin values under $25 \mathrm{ng} / \mathrm{mL}$ and 0.107 and 0.182 in leptin values above $25 \mathrm{ng} / \mathrm{mL}$ ). The $P$ values at femoral neck and lumbar spine regions were 0.575 and 0.335 in values $\geq 25 \mathrm{ng} / \mathrm{mL}$ and 0.685 and 0.857 in values $<25 \mathrm{ng} / \mathrm{mL}$ that were not significant (Tables 3 and 4).

\section{Discussion}

Our data on total serum leptin in our patients confirmed the gender dimorphism. The leptin levels in females were five times higher than males $(42.38 \pm 39.75$ versus $13.08 \pm 8.07)$. Other studies also showed this priority in females (27-31). Considine et al pointed out that women and men with equivalent percentages of body fat had comparable levels of serum leptin. We did not have this type of comparison in our cases (32). In the study by Ahmadi et al, leptin levels were higher in males than in females (24). In healthy general population $(\mathrm{BMI}<25)$ leptin level in women was measured to be more than that of men (women; $6.9 \pm 4.3$ versus men; $5.6 \pm 2.2)(P \leq 0.05)(33)$.

$\mathrm{BMI}$ in our female patients was significantly higher than males (23.656 \pm 3.72 versus $22.136 \pm 3.45 ; P=0.034)$. In assessment of correlation between leptin levels and BMI, in all patients, a positive and significant correlation between them was seen $(P<0.001, P=0.017$ and $P<0.001$, respectively). Except in the study by Ahmadi et al (24), which they did not find any correlation between leptin and BMI, the majority of other studies find a significant correlation between them (15,27-31).

In assessment of correlation between serum leptin level and BMD, various studies were published $(24,27,28,34)$. In all studies that were done at femoral neck and lumbar spine, any correlation between leptin level and BMD was detected $(24,27,28)$. However, this correlation at different sites of radius bone (compact bone) was found to be significant $(27,34)$. In this study we investigated this relationship in our patients. We selected young and middle-aged patients (20-55 years) and thus we have tried to limit the effect of the senile osteoporosis as a confounder agent. However, we did not find any significant correlation between leptin level and BMD in our patients. In this study we used Z-score as a main indicator of BMD in our patients in order to access to more real information instead of T-score, and also from same definitions that used in general population. Polynomial regression analysis showed that the correlation curve between the BMD Z-score and serum leptin had a flat U-shape with an inflexion point of $25 \mathrm{ng} / \mathrm{mL}$ of serum leptin. This cor- 
Table 3. Correlation between leptin $\geq 25$ and BMD in femoral neck \& lumbar spine region (Z-score)

\begin{tabular}{llcc}
\hline & & Femoral-Z & Lumbar-Z \\
\hline \multirow{2}{*}{ Leptin $(\mathrm{ng} / \mathrm{mL})$} & Correlation & 0.107 & 0.182 \\
& $P$ value & 0.575 & 0.335 \\
\hline
\end{tabular}

Table 4. Correlation between leptin $<25$ and BMD in femoral neck \& lumbar spine region (Z-score)

\begin{tabular}{llcc}
\hline & & Femoral-Z & Lumbar-Z \\
\hline \multirow{2}{*}{ Leptin $(\mathrm{ng} / \mathrm{mL})$} & Correlation & -0.053 & -0.024 \\
& $P$ value & 0.685 & 0.857 \\
\hline
\end{tabular}

responds with saturation threshold previously expressed by Caro et al (33) and Ghazali et al (27) who suggested a threshold (17-24 ng/mL) in their patients. We also detected approximately the same threshold in our patients. Under this threshold the relationship ( $r$ ) between leptin and bone mass was negative $(r=-0.053,-0.024$ for femoral neck and lumbar region respectively), and above that this relation $(r)$ was positive $(r=0.107,0.182$ for femoral neck and lumbar region respectively). As mentioned earlier, $P$ values at femoral and lumbar region were 0.575 and 0.335 in values $\geq 25 \mathrm{ng} / \mathrm{mL}$ of leptin and 0.685 and 0.857 in values $<25 \mathrm{ng} / \mathrm{mL}$ of leptin that were not significant. In Ghazali et al (27) study in patients with serum leptin above the curve inflexion point, they showed significant positive correlations at both radius sites $(\mathrm{r}=0.53, P=0.03$ at midshaft radius and $\mathrm{r}=0.50, P=0.04$ at ultradistal radius). Ghazali et al also did not find any significant correlation at femoral neck level (27).

An interesting point is that in all investigations performed until now, bone biopsy from iliac crest has been as gold standard test for detection of bone changes. As mentioned earlier, while, in the majority of studies done until now, no significant relations between lumbar spine density and leptin level has been detected, all bone biopsies are done on this region. This is done in spite of the fact that assuming any significant and meaningful relation in this context may seem irrational.

Trabecular bones in our body have different roles. For example, metabolic and weight bearing roles. They are very accessible and walkaway in view of their structures. For these reasons and several other factors that we do not know about them. It seems that they are not good candidates for leptin effect assessments. However, cortical bones seem to be less under metabolic and weight bearing effects in our body and therefore they can be better representor of pure bone changes in bone diseases. Jamal et al in 2007 showed that cortical bones (ultra-distal radius) had significant differences in bone density between two groups of dialysis patients with and without fractures (35). In Ghazali et al (27) and Coen et al (29) studies also, a significant relation between bone density at mid-shaft and ultra-distal of radius and leptin level was detected.

\section{Conclusion}

We believe that leptin has a bimodal effect on bone mass with a threshold as previously mentioned in the studies of
Caro et al (33) and Ghazali et al (27). Maybe the assessment of this effect has not been shown correctly by iliac crest bone biopsy as a trabecular bone. Cortical bones assessment may be better candidate.

\section{Limitations of the study}

The limitation of our study was small sample size of voluntary patients. Therefore, a multicenter trial may result in a better revaluation of this aspect of HD patients.

\section{Acknowledgements}

The authors wish to thank HD wards of Imam-Reza and Montaseriyeh hospitals of Mashhad University of Medical Sciences, Mashhad, Iran, to support this study and all the colleagues and nurses who participated in the data collecting process.

\section{Authors' contribution}

All authors contributed to design of the research. FN supervised the research. MGS conducted the research and prepared the manuscript. RJDB helped in collection and analyzing the data. MN, MTS and SAS commented, gave their advice and helped during the research. All authors read, revised and approved the final manuscript.

\section{Conflicts of interest}

The authors declare that they have no conflicting interest.

\section{Ethical considerations}

Ethical issues (including plagiarism, data fabrication, double publication) have been completely observed by authors.

\section{Funding/Support}

This manuscript is issued from the nephrology fellowship thesis of Mahin Ghorban-Sabbagh and was supported financially by Mashhad University of Medical Sciences, Mashhad, Iran (Grant\# t-2436).

\section{References}

1. Moorthi RN, Moe SM. Recent advances in the noninvasive diagnosis of renal osteodystrophy. Kidney Int. 2013;84:88694. doi: 10.1038/ki.2013.254.

2. Merabet E, Dagogo-Jack S, Coyne DW, Klein S, Santiago JV, Hmiel SP, et al. Increased plasma leptin concentration in end-stage renal disease. J Clin Endocrinol Metab. 1997;82:847-50. doi: 10.1210/jc.82.3.847.

3. Cheung W, Yu PX, Little BM, Cone RD, Marks DL, Mak $\mathrm{RH}$. Role of leptin and melanocortin signaling in uremiaassociated cachexia. J Clin Invest. 2005;115:1659-65. doi: 10.1172JCI22521.

4. Burguera B, Hofbauer LC, Thomas T, Gori F, Evans GL, Khosla S, et al. Leptin reduces ovariectomy-induced bone loss in rats. Endocrinology. 2001;142:3546-53. doi: 10.1210/ endo.142.8.8346.

5. Steppan CH, Crawford T, Chidsey-Fink KL, Ke H, Swick AG. Leptin is a potent stimulator of bone growth in ob/ ob mice. Regul Pept. 2000;92:73-8. doi: 10.1016/S01670115(00)00152-X.

6. Ducy P, Amling M, Takeda S, Priemel M, Schilling AF, Beil FT, et al. Leptin inhibits bone formation through a hypothalamic relay. Cell. 2000;100:197-207. doi: 10.1016/ S0092-8674(00)81558-5.

7. Barbour KE, Zmuda JM, Boudreau R, Strotmeyer ES, 
Horwitz MJ, Evans RW, et al. The effects of adiponectin and leptin on changes in bone mineral density. Osteoporos Int. 2012;23:1699-710. doi: 10.1007/s00198-011-1768-x.

8. Sherk VD, Malone SP, Bemben MG, Knehans AW, Palmer IJ, Bemben DA. Leptin, fat mass, and bone mineral density in healthy pre- and postmenopausal women. J Clin Densitom. 2011;14:321-5. doi: 10.1016/j.jocd.2011.03.010.

9. Koroglu BK, Kiris F, Ersoy IH, Sutcu R, Yildiz M, Aksu O, et al. Relation of leptin, adiponectin and insulin resistance to bone mineral density in type 2 diabetic postmenopausal women. Endokrynol Pol. 2011;62:429-35.

10. Iida T, Domoto T, Takigawa A, Nakamura S, Kato Y, Togo $\mathrm{M}$, et al. Relationships among blood leptin and adiponectin levels, fat mass, and bone mineral density in Japanese pre- and postmenopausal women. Hiroshima J Med Sci. 2011;60:71-8.

11. Zhang H, Xie H, Zhao Q, Xie GQ, Wu XP, Liao EY, et al. Relationships between serum adiponectin, apelin, leptin, resistin, visfatin levels and bone mineral density, and bone biochemical markers in post-menopausal Chinese women. J Endocrinol Invest. 2010;33:707-11. doi: 10.1007/ BF03346674.

12. Wu N, Wang QP, Li H, Wu XP, Sun ZQ, Luo XH. Relationships between serum adiponectin, leptin concentrations and bone mineral density, and bone biochemical markers in Chinese women. Clin Chim Acta. 2010;411:771-5. doi: 10.1016/j. cca.2010.02.064

13. Rhie YJ, Lee KH, Chung SC, Kim HS, Kim DH. Effects of body composition, leptin, and adiponectin on bone mineral density in prepubertal girls. J Korean Med Sci. 2010;25:118790. doi: 10.3346/jkms.2010.25.8.1187.

14. King GA, Deemer SE, Thompson DL. Relationship between leptin, adiponectin, bone mineral density, and measures of adiposity among pre-menopausal hispanic and caucasian women. Endocr Res. 2010;35:106-17. doi: 10.3109/07435800.2010.496090.

15. Yilmaz A, Nur N, Turgut B. Leptin and bone mineral density in haemodialysis patients. Ann Acad Med Singapore. 2009;38:374-4.

16. Yang LC, Lan Y, Hu J, Yang YH, Zhang Q, Piao JH. Correlation of serum leptin level with bone mineral density and bone turnover markers in Chinese adolescent dancers. Biomed Environ Sci. 2009;22:369-73.

17. Oguz S, Tapisiz OL, Aytan H, Gunyeli I, Erdem S, Tuncay $\mathrm{G}$, et al. Is leptin a significant predictor of bone mineral density in postmenopausal Turkish women. Rheumatol Int. 2009;29:393-6. doi: 10.1007/s00296-008-0711-8.

18. Lei X, Peng X, Wu N, Hu M, Sun Z. Serum adiponectin, leptin level, and bone mineral density in postmenopausal women. Zhong Nan Da Xue Xue Bao Yi Xue Ban. 2009;34:559-62.

19. Yang LF, Xie H, Yuan LQ, Wu XP. Serum adiponectin and leptin levels and bone mineral density in 232 men. Zhong Nan Da Xue Xue Bao Yi Xue Ban. 2008;33:523-6.

20. Tamura T, Yoneda M, Yamane K, Nakanishi S, Nakashima $\mathrm{R}$, Okubo $\mathrm{M}$, et al. Serum leptin and adiponectin are positively associated with bone mineral density at the distal radius in patients with type 2 diabetes mellitus. Metabolism. 2007;56:623-8. doi: 10.1016/j.metabol.2006.12.008.

21. Zoico E, Zamboni M, Di Francesco V, Mazzali G, Fantin
F, De Pergola G, et al. Relation between adiponectin and bone mineral density in elderly post-menopausal women: role of body composition, leptin, insulin resistance, and dehydroepiandrosterone sulfate. J Endocrinol Invest. 2008;31:297-302. doi: 10.1007/BF03346361.

22. Filip R, Raszewski G. Bone mineral density and bone turnover in relation to serum leptin, $\alpha$-ketoglutarate and sex steroids in overweight and obese postmenopausal women. Clin Endocrinol. 2009;70:214-20.

23. do Prado WL, de Piano A, Lazaretti-Castro M, de Mello MT, Stella SG, Tufik S, et al. Relationship between bone mineral density, leptin and insulin concentration in Brazilian obese adolescents. J Bone Miner Metab. 2009;27:613-9.

24. Ahmadi F, Salari S, Maziar S, Esfahanian F, Khazaeipour Z, Ranjbarnovin N. Relationship between serum leptin levels and bone mineral density and bone metabolic markers in patients on hemodialysis. Saudi J Kidney Dis Transpl. 2013;24:41-7. doi: 10.4103/1319-2442.106238.

25. Janaina M, João HC, Barbara V, Rogerio O, Vanda J, Jacqueline TC. Correlations between leptin and bone microarchitecture in hemodialysis patients. Nephrol Dial Transplant. 2013;28:158. doi:10.1093/ndt/gft110.

26. Rezaieyazdi Z, Falsoleiman H, Khajehdaluee M, Saghafi M, Mokhtari-Amirmajdi E. Reduced bone density in patients on long-term warfarin. Int J Rheum Dis. 2009;12:130-5. doi: 10.1111/j.1756-185X.2009.01395.X.

27. Ghazali A, Grados F, Oprisiu R, Bunea D, Morinière P, El Esper N, et al. Bone mineral density directly correlates with elevated serum leptin in hemodialysis patients. Nephrol Dial Transplant. 2003; 18:1882-90. doi: 10.1093/ndt/gfg268.

28. Polymeris A, Doumouchtsis K, Grapsa E. Bone mineral density and bone metabolism in hemodialysis patients. Correlation with PTH, 25OHD3 and leptin. Nefrologia. 2012;32:73-8. doi: 10.3265/Nefrologia.pre2011.

29. Coen G, Ballanti P, Fischer MS, Balducci A, Calabria S, Colamarco L, et al. Serum leptin in dialysis renal osteodystrophy. Am J Kidney Dis. 2003; 42:1036-42. doi: 10.1016/j.ajkd.2003.07.005

30. Zoccali C, Panuccio V, Tripepi G, Cutrupi S, Pizzini P, Mallamaci F. Leptin and biochemical markers of bone turnover in dialysis patients. J Nephrol. 2004; 17:253-60.

31. Nasri H. Association of serum leptin with various biochemical parameters of bone turnover in maintenance hemodialysis patients. Pak J Nutr. 2006;5:180-4.

32. Considine RV, Sinka MK, Heiman ML, Krianciunas A, Bauer TL, Caro JF. Serum immunoreactive leptin concentrations in normal weight and obese human. $\mathrm{N}$ Engl J Med. 1996;334:292-5. doi: 10.1056/NEJM199602013340503.

33. Caro JF, Kolaczynski JW, Nyce MR, Ohannesian J, Considine RV. Decreased cerebrospinal fluid/serum leptin ratio in obesity: a possible mechanism for leptin resistance. Lancet. 1996;348:159-61. doi: 10.1016/S0140-6736(96)03173-X.

34. Yaghmaei PA, Pouyamanesh Z, Sh O, Hoghoughirad L, Hedayati M. Relationship of serum leptin level with papillary thyroid cancer in Iranian patients. Trauma Mon. 2011;2011:61-5.

35. Jamal SA, Hayden JA, Beyene J. Low bone mineral density and fractures in long-term hemodialysis patients: a metaanalysis. Am J Kidney Dis. 2007;49:674-81

Copyright (c) 2016 The Author(s); Published by Nickan Research Institute. This is an open-access article distributed under the terms of the Creative Commons Attribution License (http://creativecommons.org/licenses/by/4.0), which permits unrestricted use, distribution, and reproduction in any medium, provided the original work is properly cited. 